\title{
Similarities and Differences in Physiological Responses to 'Candidatus Liberibacter solanacearum' Infection Among Different Potato Cultivars
}

\author{
C. M. Wallis, A. Rashed, A. K. Wallingford, L. Paetzold, F. Workneh, and C. M. Rush
}

First and third authors: United States Department of Agriculture-Agricultural Research Service San Joaquin Valley Agricultural Sciences Center, Parlier, CA 93648; and second, fourth, fifth, and sixth authors: Texas A\&M AgriLife Research, Amarillo 79106. Current address of second author: University of Idaho, Aberdeen Research \& Extension Center, Aberdeen 83210 Accepted for publication 2 August 2013

\begin{abstract}
Wallis, C. M., Rashed, A., Wallingford, A. K., Paetzold, L., Workneh, F., and Rush, C. M. 2014. Similarities and differences in physiological responses to 'Candidatus Liberibacter solanacearum' infection among different potato cultivars. Phytopathology 104:126-133.

Zebra chip disease (ZC), putatively caused by the fastidious bacterium 'Candidatus Liberibacter solanacearum', is a threat to potato growers worldwide. However, little is known about biochemical shifts in different potato genotypes in response to ' $\mathrm{Ca}$. L. solanacearum' infection. To address this, 'Red La Soda', 'Russet Norkotah', and 'FL 1867' potato were infected with ' $C a$. L. solanacearum' $4,3,2$, and 1 weeks before harvest to observe variability in cultivar responses to ' $\mathrm{Ca}$. L. solana-

symptoms when infected for 4 weeks than Russet Norkotah or FL 1867 tubers. ' $\mathrm{Ca}$. L. solanacearum' titers did not vary among cultivars. Tuber levels of amino acids, carbohydrates, and phenolics varied among cultivars but no consistent trends were observed. Individual amino acids and phenolics were greater in FL 1867 than Red La Soda, whereas others were greater in Red La Soda or Russet Norkotah than FL 1867. Most amino acids, carbohydrates, and phenolics were positively associated with infection duration and symptoms regardless of cultivar. Associations between most of the evaluated compounds and ' $\mathrm{Ca}$. L. solanacearum' titer were positive in Red La Soda. However, no associations between ' $C a$. L. solanacearum' quantity and compounds were observed in FL 1867 and Russet Norkotah.
\end{abstract} cearum' infection. ZC symptoms, 'Ca. L. solanacearum' titers, and tuber biochemistry were assessed. Red La Soda tubers exhibited greater
Additional keyword: bacteria.
Zebra chip disease (ZC) of potato (Solanum tuberosum L.), putatively caused by 'Candidatus Liberibacter solanacearum', is an emerging threat to potato production in Central America, North America, and New Zealand $(4,5,13,19,27)$. There also is great concern that ZC may spread to other potato-growing areas (11). 'Ca. L. solanacearum' (also known as ' $C a$. L. psyllaurous') is a recently identified phloem-limited, gram-negative bacteria spread by the tomato and potato psyllid, Bactericera cockerelli (Sulc.) (21). Two 'Ca. L. solanacearum' haplotypes exist that infect potato (' $\mathrm{Ca}$. L. solanacearum' A and ' $\mathrm{Ca}$. L. solanacearum' B), although biological differences between the haplotypes have yet to be determined (21).

Characteristic ZC symptoms in tubers include brown discoloration of freshly cut and fried potato products (including "zebra stripes" of potato chips or crisps) $(17,28)$. Aboveground ZC symptoms include plant dwarfing, formation of aerial tubers, leaf scorch, chlorosis, and vine collapse $(17,28)$. These aboveground ZC symptoms are similar to those of psyllid yellows, a condition caused by potato psyllid feeding even in the absence of detectable 'Ca. L. solanacearum' (29). However, ZC symptoms of tubers do not occur with psyllid yellows, and ' $C a$. L. solanacearum'infected potato plants die more rapidly than ' $\mathrm{Ca}$. L. solanacearum'-negative plants that are expressing psyllid yellows (29). Current management of ZC involves costly $(\approx \$ 700 / \mathrm{ha})$ chemical control programs for the tomato and potato psyllid vector, which

Corresponding author: C. Wallis; E-mail address: christopher.wallis@ars.usda.gov

http://dx.doi.org/10.1094/PHYTO-05-13-0125-R

This article is in the public domain and not copyrightable. It may be freely reprinted with customary crediting of the source. The American Phytopathological Society, 2014 often entail weekly insecticide applications (10). Long-term sustainable management would entail developing potato varieties tolerant or resistant to ' $\mathrm{Ca}$. L. solanacearum' infection, because planting these should be the most cost-effective way to prevent ZC $(17,18)$.

Prerequisite to the development of ZC-tolerant or resistant potato varieties is improved understanding of how different marketing classes of potato naturally respond to ' $\mathrm{Ca}$. L. solanacearum' infection. Previous studies showed increased levels of phenolics $(1,20,24,34)$, reducing sugars (glucose and fructose) $(2,3,9,24)$, defense-associated enzymes $(1,24,34)$, amino acids (e.g., isoleucine, leucine, serine, tyrosine, and valine) $(20,24,34)$, and minerals (e.g., phosphorus, potassium, and calcium) (15) in potato plants infected with ' $\mathrm{Ca}$. L. solanacearum'. Many of these physiological changes could be attributed to increased occurrence of hypersensitive responses in plants infected by ' $\mathrm{Ca}$. L. solanacearum' (16). Studies further revealed that increases in these compounds occurred over time, with phenolic and reducing sugar levels in tubers plateauing between 3 and 5 weeks after infection (24). This time range is similar to when ZC symptoms begin to develop after initial ' $C a$. L. solanacearum' infection $(2,12)$. ZC symptoms in tubers were positively correlated with phenolics, sugars, particular amino acids, and enzyme levels $(24,34)$. Greater levels of phenolics and polyphenol oxidases were concluded to be positively associated with browning of freshly cut potato, because polyphenol oxidases convert phenolics into brown-colored products $(14,34)$. Likewise, increased levels of reducing sugars and amino acids would contribute to increased browning of fried potato products, because acrylamide formation occurs using these two compound classes as substrates at frying temperatures via the Maillard reaction $(8,30,34)$. 
Despite positive correlations between changes in tuber biochemistry and ZC symptom severity, the titer of ' $\mathrm{Ca}$. L. solanacearum' in infected tubers has not yet been found to be associated with changes in tuber biochemistry, although the presence of ' $\mathrm{Ca}$. L. solanacearum' in the tuber does appear to be required for initiation of these changes $(24,34)$. It is possible that, once biochemical changes began to plateau $\approx 3$ to 5 weeks after ' $C a$. L. solanacearum' infection, levels of defense-associated compounds inhibit ' $C a$. L. solanacearum' development, a possibility which may explain failures to detect any significant association between ' $\mathrm{Ca}$. L. solanacearum' quantity and biochemical shifts in tuber biochemistry. Focusing on initial stages of ' $\mathrm{Ca}$. L. solanacearum' titer and ZC development would help the evaluation of whether ' $\mathrm{Ca}$. L. solanacearum' quantity is associated with ZC-associated shifts in tubers biochemistry.

The differences in physiological responses to ' $C a$. L. solanacearum' infection among potato cultivars are poorly understood. Previous studies examining potato biochemical responses to 'Ca. L. solanacearum' infection have focused on chipping potato cultivars such as 'Atlantic' and 'FL 1867' (2,20,24,34). Anecdotally, there is some evidence that red potato cultivars are less susceptible to ZC than other market classes such as russet varieties. However, despite observed among-cultivar variability in susceptibility to $\mathrm{ZC}$, no tested potato variety was found to be completely resistant to ' $\mathrm{Ca}$. L. solanacearum' infection (18).

The objectives of this study were to characterize ZC symptom development, increases in ' $C a$. L. solanacearum' titers, and ZCassociated changes in tuber biochemistry that occur up to 4 weeks post inoculation in three different potato cultivars, each belonging to different market classes (i.e., chipping, red, or russet potato). The time course of this study allowed higher resolution for detecting shifts in host biochemistry that occur immediately following 'Ca. L. solanacearum' infection. Examining three different potato cultivars from different market classes maximized chances to detect potential differences in physiological responses to ' $\mathrm{Ca}$. L. solanacearum' infection because different potato market types possess different biochemical properties $(6,31,33)$. For instance, various cultivars of the red marketing type possessed greater levels of glucoside or fructose and phenolics than cultivars of the russet marketing type, whereas levels of asparagine were greater in russet potato than in red potato $(6,33)$. Also, a chipping potato cultivar ('Kennebec') was observed to have lower sugar and phenolic content than either red or russet cultivars (6). Therefore, this study observed whether differences among cultivars in initial or ' $\mathrm{Ca}$. L. solanacearum' infection-induced tuber biochemistry resulted in differences in $\mathrm{ZC}$ symptom progression.

\section{MATERIALS AND METHODS}

Experimental design. Field experiments were conducted in summer 2012 at the Texas A\&M AgriLife Research and Extension Center in Bushland. Seed potato tubers of FL 1867 (chipping potato type), 'Red La Soda' (red potato type), and 'Russet Norkotah' (russet potato type) were planted on 19 April 2012 and covered with 100-by-100-by-100-cm tent-shaped mesh cages prior to plant emergence. After emergence in May, plants in each cage were thinned, such that each cage contained four plants of the same cultivar.

Greenhouse reared ' $C a$. L. solanacearum'-positive potato psyllids of central haplotype (32), which consisted of a mix of biotypes ' $C a$. L. solanacearum' haplotypes A and B (35), were used to infest the potato plants in the experimental cages. These colonies were known to have a $97 \%$ positive frequency based on a previous evaluation conducted in an independent study (24). Before every infestation event, a composite sample of 5 to 10 psyllid from each colony was tested to reconfirm the ' $\mathrm{Ca}$. L. solanacearum'-positive status of the colony.
Four times (4, 3, 2, and 1 weeks prior to harvest), different cages were infested by releasing 30 potato psyllids from the ' $\mathrm{Ca}$. L. solanacearum'-positive colonies at the base of a single plant in each cage. For each cultivar and infestation combination, there were four cage-replicates arranged in a randomized complete block design. Infested psyllids were allowed to remain on the plants for 1 week, at which time the plants were thoroughly sprayed with a mix of Movento (Bayer CropScience), Agri-Mek, and Fulfill (Syngenta Crop Protection, LLC). Insecticides were reapplied 1 week later to ensure complete psyllid removal. Additional cages were left noninfested as negative controls. In this study, controls are represented as plants with the infection duration of " 0 ".

All experimental cages were harvested on 26 July 2012. Harvested tubers from all experimental plants were transferred to the laboratory for processing. Four tubers per plant were randomly selected for biochemical and ' $C a$. L. solanacearum' quantifications. A 5-mm-thick slice was removed from the basal end (stolon attachment end) and scored for ZC symptom severity on a 0 to 3 scale following Rashed et al. (24) and Wallis et al. (34), which both provide visual representations of the rating scale. In brief, $0=$ no browning observed; $1=$ small flecks of browning; $2=$ widespread but light browning; and $3=$ dark, widespread browning. These samples were then used for biochemical analyses according to the methods below.

A second slice ( 2 to $3 \mathrm{~mm}$ thick) was taken and stored at $-80^{\circ} \mathrm{C}$ for quantification of ' $C a$. L. solanacearum' titers by quantitative polymerase chain reaction (qPCR) according to the methods of Rashed et al. (24). In brief, ground tuber material had DNA extracted by following a slightly modified DNeasy Plant Mini Kit (Qiagen, Valencia, CA) protocol. This DNA was then used in qPCR reaction performed using an Applied Biosystems (Carlsbad, CA) 7500 Real-Time PCR System, a reaction mix containing TaqMan Universal Master Mix (Applied Biosystems), $0.3 \mu \mathrm{M}$ forward primer $\mathrm{LsoF}, 0.3 \mu \mathrm{M}$ reverse primer $\mathrm{HLBr}$, and $0.25 \mu \mathrm{M}$ HLBp TaqMan probe. The comparative cycle threshold method $(\Delta \Delta \mathrm{Ct})$ was used for ' $C a$. L. solanacearum' relative quantification, by which pathogen quantity in target samples was normalized in relation to a calibrator and an endogenous 18s RNA control (24).

Biochemical analyses. Tuber samples were sent overnight on dry ice to United States Department of Agriculture (USDA) Agricultural Research Service San Joaquin Valley Agricultural Sciences Center in Parlier, CA. Samples were then stored at $-20^{\circ} \mathrm{C}$ until biochemical analyses were performed.

Samples were processed by mashing $5 \mathrm{~g}$ of tuber tissue (removed with a 12 -mm cork borer) using a mortar and pestle. From the mashed tissue, two 0.10 -g aliquots were weighed, placed into separate $1.5 \mathrm{ml}$ microcentrifuge tubes, and flash-frozen in liquid nitrogen to prevent oxidation.

The methods of Wallis et al. (34) and Rashed et al. (24) were used to analyze tuber biochemistry. In brief, one aliquot of $0.10 \mathrm{~g}$ of tuber tissue was twice-extracted overnight at $4^{\circ} \mathrm{C}$ with $0.5 \mathrm{ml}$ of methanol (Sigma-Aldrich, St. Louis) to yield $1 \mathrm{ml}$ of methanol extract. This methanol extract was injected into a Shimadzu (Columbia, MD) high-performance liquid chromatography (HPLC) system to analyze phenolic compounds (34). Compounds were quantified and identified as described previously by Wallis et al. (34) and Rashed et al. (24). In brief, commercial standards (Sigma-Aldrich) were obtained and used to match retention times and UV/Vis spectra of peaks for confirmation of compound identifications as well as to convert identified compounds to gram amounts. When commercial standards were not available, peaks were converted to gram amounts using compounds within the same compound class (24). Liquid-chromatography mass spectrometry using the same gradient as HPLC analyses also aided in putatively identifying compounds (24). In sum, a total of 14 phenolic compounds were quantified in this study, with the details of identification described by Rashed et al. (24). 
The second 0.10 -g aliquot was twice-extracted overnight at $4{ }^{\circ} \mathrm{C}$

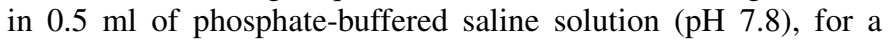
combined $1 \mathrm{ml}$ of extract. In total, $100 \mu \mathrm{l}$ of the buffer extract was used to assess amino acids following the protocol of a commercially available kit from Phenomenex (Torrance, CA), which used a Shimadzu 2010 GC-FID gas chromatograph and a Zebron AAA column. In total, 15 amino acids were quantified.

Another $100 \mu \mathrm{l}$ of the buffer extract was injected into a Shimadzu HPLC equipped with a 300-by-7.8-mm Supelco C-611 carbohydrate column (Sigma-Aldrich) and a refractive index detector (RID-10 from Shimadzu) for analysis of carbohydrates, according to the methods of Rashed et al. (24). Appropriate sugar standards (Sigma-Aldrich) were used to convert peak areas to gram amounts (24).

Statistical analyses. IBM-SPSS software (version 19.0; IBM, Armonk, NY) was used for all statistical analyses. Data were assessed for normality by plotting residuals and outliers (data greater than two standard errors of a mean) were removed. Kruskal-Wallis tests followed by Mann-Whitney U tests (for pairwise separations) were used to detect differences in $\mathrm{ZC}$ severity due to potato cultivar at each infestation period (with noninfected controls not included in analyses).

Differences in ' $\mathrm{Ca}$. L. solanacearum' titers among potato cultivars overall and at each infection period (with negative controls excluded) were determined by analysis of variance (ANOVA). Post hoc Tukey honestly significant difference (HSD) tests were used to determine significant differences between cultivars.

To examine cultivar differences in constitutive (preinfection) tuber chemistry, multivariate ANOVAs (MANOVAs) were utilized to examine differences in noninfected tubers only, with potato cultivar and plant replicate as the dependent variables. To increase statistical power, plant replicate was removed from the final model if it was nonsignificant $(P>0.05)$. If significant differences were detected by MANOVA, ANOVA and subsequent Tukey HSD tests were performed to observe differences in tuber compounds between cultivars.

To confirm differences between chemical profiles of infected potato and noninfected potato, MANOVAs were utilized with potato cultivar, infection duration (noninfected controls or ' $\mathrm{Ca}$. L. solanacearum'-infected tubers), and plant replicate (1 to 4) as independent categorical variables. To increase statistical power, plant replicate factor was removed from the final model if its effect was nonsignificant $(P>0.05)$

To examine cultivar differences in tuber chemistry after ' $\mathrm{Ca}$. L. solanacearum' infection, multivariate analyses of covariance (MANCOVAs) were used to examine effects of potato cultivar, infection duration $(4,3,2$, or 1 weeks before harvest), the interaction (cultivar-duration), and plant replicate (1 to 4) while controlling for ' $\mathrm{Ca}$. L. solanacearum' titer (as a co-variable) on amino

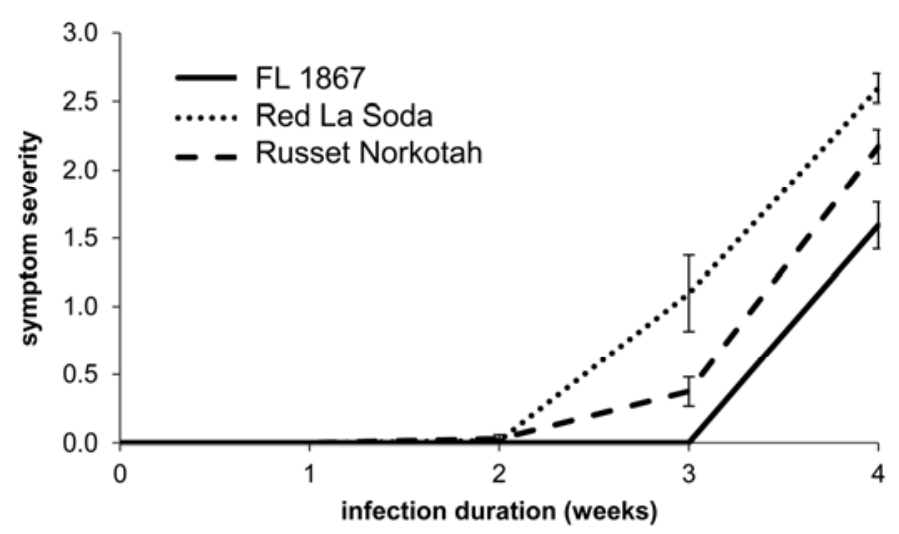

Fig. 1. Changes in zebra chip disease symptom severity (scale of 0 to 3) during the course of 'Candidatus Liberibacter solanacearum' infection for three different cultivars of potato. Bars represent standard error. acid, phenolic, or carbohydrate levels (with separate analyses for each compound group). To increase statistical power, plant replicate and ' $C a$. L. solanacearum' titer were removed from the final models if effects were nonsignificant $(P>0.05)$. Each MANCOVA (or MANOVA) was followed by multiple ANOVAs to determine individual compounds which were significantly affected within a biochemical class. For pairwise comparisons among potato cultivars and infection duration, Tukey HSD tests were used.

Pearson correlations were used to determine associations between compound levels and ' $\mathrm{Ca}$. L. solanacearum' titers. Spearman $\rho$ correlations were used to determine associations between tuber compound levels, infection durations, and $\mathrm{ZC}$ symptom ratings.

\section{RESULTS}

Potato cultivar effect on $\mathrm{ZC}$ severity and ' $\mathrm{Ca}$. L. solanacearum' titer. Overall, symptoms were significantly greater (Kruskal-Wallis $H=119.511, P<0.001, N=172$ ) in plants inoculated 4 weeks before harvest than other durations, and significantly greater in plants inoculated 3 weeks before harvest than any shorter ' $C a$. L. solanacearum' infection duration. ZC symptoms were significantly more severe in Red La Soda than Russet Norkotah or FL 1867 tubers, and more severe in Russet Norkotah than FL $1867(H=8.652, P=0.013, N=172)$. ZC symptoms also were greater in Red La Soda potato than the other cultivars when only potato plants infected for 3 weeks $(H=14.537, P=0.001$, $N=41)$ or 4 weeks $(H=21.845, P<0.001, N=47)$ prior to harvest were considered (Fig. 1). However, when only considering potato plants infected 1 and 2 weeks before harvest, no significant differences between cultivars were observed $(P>0.05)$ (Fig. 1).

' $C a$. L. solanacearum' titers within tubers infected at the same time did not differ significantly among potato cultivars $(F=$ $0.268, P=0.765, N=210$ ). However, 'Ca. L. solanacearum' titers did differ due to infection duration $(F=21.425, P<0.001, N=$ 168), with infections of 3 or 4 weeks having greater ' $\mathrm{Ca}$. L. solanacearum' titers than plants infected for 1 or 2 weeks.

ZC symptoms and ' $C a$. L. solanacearum' titers were significantly positively correlated (Spearman $\rho=0.613, P<0.001, N=$ 168).

Potato cultivar and infection duration effects on tuber amino acids. MANOVA on noninfected tubers revealed significant differences in tuber amino acid levels due to cultivar (Pillai's Trace $\Lambda=1.821, F=11.514, P<0.001, N=41)$. Follow-up ANOVAs revealed significant differences $(P<0.05)$ in the levels of all individual amino acids, with the exception of asparagine and histidine. Pairwise post hoc Tukey HSD tests revealed that FL 1867 tubers had significantly greater $(P<0.05)$ levels of leucine, glutamic acid, ornithine, lysine, and tryptophan than Red La Soda or Russet Norkotah tubers. By contrast, Red La Soda had significantly greater $(P<0.05)$ levels of valine, isoleucine, serine, proline, methionine, phenylalanine, and glutamine than FL 1867. Russet Norkotah tubers possessed amino acid levels that generally were in between those of the other cultivars, although Russet Norkotah levels of aspartic acid were greater $(P<0.05)$ than Red La Soda or FL 1867 levels.

MANOVA confirmed that amino acid levels in ' $\mathrm{Ca}$. L. solanacearum'-infected tubers were significantly greater than levels in noninfected tubers $(\Lambda=0.451, F=9.250, P<0.001, N=206)$.

MANCOVA was performed to examine differences due to cultivars and durations of ' $\mathrm{Ca}$. L. solanacearum' infection on amino acid levels while holding ' $C a$. L. solanacearum' titer as a covariable. However, due to nonsignificant effect of titer $(\Lambda=$ $0.078, F=0.556, P=0.901, N=161)$, this co-variable was removed. MANOVA determined significant effects due to cultivar $(\Lambda=1.790, F=59.228, P<0.001, N=161)$, infection duration $(\Lambda=1.785, F=10.279, P<0.001, N=161)$, and plant replicate $(\Lambda=0.810, F=2.587, P<0.001, N=161)$ on tuber amino acid 
content. There also was a significant interaction between cultivar and infection duration $(\Lambda=2.122, F=3.941, P<0.001, N=$ 161). Subsequent ANOVAs suggested that cultivar significantly $(P<0.05)$ affected levels of most quantified amino acids except tryptophan. Infection duration significantly $(P<0.05)$ affected levels of every amino acid measured. There also were significant $(P<0.05)$ cultivar-infection duration interactions for every compound except glutamic acid, caused mainly by differences in amino acids among cultivars becoming more pronounced at longer infection durations.

According to Tukey HSD tests, infected FL 1867 tubers had significantly less valine, leucine, isoleucine, serine, proline, asparagine, aspartic acid, methionine, phenylalanine, glutamine, lysine, and histidine levels than infected Red La Soda or Russet Norkotah tubers. However, the FL 1867 tubers had significantly greater $(P<0.05)$ amounts of glutamic acid and ornithine than Red La Soda or Russet Norkotah tubers.

The effects of infection duration on amino acid content varied depending on particular amino acids, with some amino acids at greatest amounts in tubers infected for 1 or 2 weeks prior to harvest and others at greatest amounts in tubers infected for 3 or 4 weeks prior to harvest (Table 1).

Regardless of cultivar, correlation analyses generally determined significant negative correlations between asparagine, aspartic acid, glutamic acid, glutamine, and methionine with infection duration or ZC symptoms (Table 2). With a few exceptions, levels of the remaining analyzed amino acids were significantly positively correlated with infection duration or ZC symptoms (Table 2). Correlations between titers and amino acid levels varied among cultivars. For FL 1867, most amino acids were not significantly correlated with ' $\mathrm{Ca}$. L. solanacearum' titers (Table 2). For Red La Soda, 'Ca. L. solanacearum' titers were significantly negatively correlated with asparagine, aspartic acid, glutamic acid, glutamine, and methionine. Most of the remaining amino acids (except histidine, lysine, and valine) were significantly positive correlated with ' $\mathrm{Ca}$. L. solanacearum' titers in Red La Soda tubers (Table 2). For Russet Norkotah, ' $\mathrm{Ca}$. L. solanacearum' titers were significantly negatively correlated with aspartic acid and glutamic acid, whereas levels of histidine, isoleucine, leucine, lysine, ornithine, phenylalanine, proline, tryptophan, and valine were significantly positively correlated with ' $\mathrm{Ca}$. L. solanacearum' titers (Table 2).

Potato cultivar and infection duration effects on tuber carbohydrates. MANOVA on noninfected tubers revealed significant differences in tuber carbohydrate levels due to cultivar
( $\Lambda=1.106, F=12.372, P<0.001, N=42$ ). Follow-up ANOVAs revealed significant differences $(P<0.05)$ in the levels of fructose, glucose, and sucrose. Tukey HSD results indicated that FL 1867 tubers had significantly greater $(P<0.05)$ levels of fructose and sucrose than Red La Soda or Russet Norkotah tubers. Furthermore, FL 1867 and Russet Norkotah tubers possessed significantly greater $(P<0.05)$ levels of glucose than Red La Soda tubers.

MANOVA confirmed that carbohydrate levels in ' $\mathrm{Ca}$. L. solanacearum'-infected tubers were significantly greater than levels in noninfected tubers $(\Lambda=0.153, F=11.418, P<0.001, N=214)$.

MANCOVA analyses on infected tubers revealed that tuber carbohydrate content was significantly affected by potato cultivar $(\Lambda=0.614, F=17.583, P<0.001, N=168)$, infection duration $(\Lambda=0.812, F=14.848, P<0.001, N=168)$, plant replicate $(\Lambda=$ $0.229, F=3.300, P=0.001, N=168)$, and the ' $C a$. L. solanacearum' titer co-variable $(\Lambda=0.100, F=4.382, P=0.006$, $N=168)$. There also was a significant interaction between cultivar and infection duration $(\Lambda=0.612, F=5.129, P<0.001$, $N=168)$. Glucose $(F=19.520, P<0.001, N=168)$ and sucrose $(F=4.233, P=0.017, N=168)$ levels were significantly affected by potato cultivar (Fig. 2$)$. Significantly greater $(P<0.05)$ levels of glucose were detected in FL 1867 tubers than Red La Soda or Russet Norkotah tubers, and significantly greater levels of sucrose were present in Red La Soda tubers compared with FL 1867 tubers (Tukey HSD, $P<0.05$ ).

Furthermore, levels of fructose $(F=75.024, P<0.001, N=$ $168)$, glucose $(F=61.406, P<0.001, N=168)$, and sucrose $(F=$ 15.947, $P<0.001, N=168)$ were significantly affected by infection duration (Fig. 2). Greater $(P<0.05)$ levels of all three sugars were detected in tubers infected for 4 weeks than other durations, and greater levels in tubers infected for 3 weeks were detected than those infected for 1 or 2 weeks (Tukey HSD, $P<$ 0.05). There also were significant $(P<0.05)$ cultivar-infection duration interactions for fructose, glucose, and sucrose. Interactions likely were due to greater differences among cultivars in carbohydrate levels occurring when tubers were infected longer (Fig. 2).

Levels of fructose and glucose were positively correlated with infection duration, ZC symptoms, and ' $C a$. L. solanacearum' titers (Table 3). Levels of sucrose were positively correlated with infection duration and ZC symptoms for Red La Soda and Russet Norkotah (Table 3). Furthermore, sucrose levels and ' $\mathrm{Ca}$. L. solanacearum' titers were positively correlated in Red La Soda (Table 3).

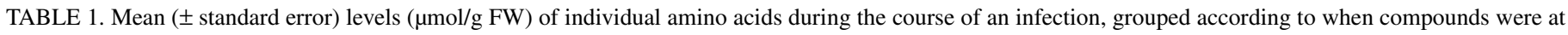
maximum amounts ${ }^{\mathrm{a}}$

\begin{tabular}{|c|c|c|c|c|c|}
\hline \multirow[b]{2}{*}{ Compound } & \multicolumn{5}{|c|}{ Infection duration (weeks) } \\
\hline & 0 & 1 & 2 & 3 & 4 \\
\hline Asparagine & $21.47 \pm 1.71$ & $28.19 \pm 2.29$ & $25.21 \pm 1.98$ & $23.05 \pm 2.04$ & $11.77 \pm 1.24$ \\
\hline Aspartic acid & $6.37 \pm 0.39$ & $7.69 \pm 0.75$ & $7.58 \pm 0.74$ & $5.45 \pm 0.78$ & $2.73 \pm 0.38$ \\
\hline Glutamic acid & $1.27 \pm 0.11$ & $1.21 \pm 0.07$ & $1.18 \pm 0.06$ & $0.69 \pm 0.06$ & $0.52 \pm 0.04$ \\
\hline Glutamine & $5.15 \pm 0.73$ & $11.77 \pm 1.76$ & $12.71 \pm 1.87$ & $8.02 \pm 1.26$ & $7.30 \pm 1.29$ \\
\hline Methionine & $0.76 \pm 0.06$ & $0.82 \pm 0.06$ & $0.69 \pm 0.04$ & $0.62 \pm 0.03$ & $0.50 \pm 0.02$ \\
\hline Histidine & $0.58 \pm 0.04$ & $0.69 \pm 0.02$ & $0.70 \pm 0.03$ & $0.78 \pm 0.06$ & $0.88 \pm 0.05$ \\
\hline Isoleucine & $0.58 \pm 0.04$ & $0.69 \pm 0.05$ & $0.70 \pm 0.05$ & $0.84 \pm 0.07$ & $1.71 \pm 0.14$ \\
\hline Leucine & $0.33 \pm 0.02$ & $0.43 \pm 0.03$ & $0.44 \pm 0.03$ & $0.90 \pm 0.13$ & $2.49 \pm 0.24$ \\
\hline Lysine & $0.73 \pm 0.09$ & $0.83 \pm 0.07$ & $1.07 \pm 0.09$ & $1.39 \pm 0.18$ & $1.83 \pm 0.20$ \\
\hline Ornithine & $0.21 \pm 0.02$ & $0.26 \pm 0.02$ & $0.23 \pm 0.02$ & $0.27 \pm 0.01$ & $0.40 \pm 0.09$ \\
\hline Phenylalanine & $0.50 \pm 0.03$ & $0.60 \pm 0.05$ & $0.62 \pm 0.05$ & $0.94 \pm 0.11$ & $0.88 \pm 0.05$ \\
\hline Proline & $0.41 \pm 0.04$ & $0.50 \pm 0.05$ & $0.60 \pm 0.05$ & $0.69 \pm 0.09$ & $1.71 \pm 0.16$ \\
\hline Serine & $7.36 \pm 0.62$ & $7.07 \pm 0.79$ & $6.55 \pm 0.60$ & $8.76 \pm 1.12$ & $9.32 \pm 0.65$ \\
\hline Tryptophan & $0.43 \pm 0.02$ & $0.56 \pm 0.02$ & $0.55 \pm 0.03$ & $0.68 \pm 0.05$ & $0.75 \pm 0.05$ \\
\hline Valine & $2.54 \pm 0.29$ & $2.81 \pm 0.31$ & $2.61 \pm 0.27$ & $3.18 \pm 0.38$ & $4.12 \pm 0.44$ \\
\hline
\end{tabular}

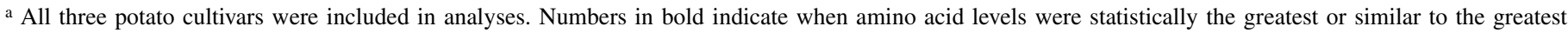
amounts, regular numbers indicate when levels were statistically the lowest amounts, and italics indicates when levels were in between the greatest or lowest amounts. Separations determined by Tukey's honestly significant difference. Noninfected amino acid levels $(0$ weeks $)$ are provided for reference. $N=164$ to 170 . 
Potato cultivar and infection duration effects on tuber phenolics. MANOVA on noninfected tubers revealed significant differences in tuber phenolic levels due to cultivar $(\Lambda=1.802, F=$ 13.965, $P<0.001, N=42$ ). Follow-up ANOVAs revealed significant differences $(P<0.05)$ in the levels of most phenolics, with the exception of the second chlorogenic acid peak, sinapic acid, and a flavonoid glucoside (flavonoid glucoside 2). According to Tukey HSD tests, FL 1867 tubers had significantly greater $(P<0.05)$ levels of chlorogenic acid (first peak), a chlorogenic acid derivative, epicatechin gallate, the putative methyl salicylate dimer, and quinic acid than Red La Soda or Russet Norkotah tubers. Russet Norkotah tubers had significantly greater $(P<$ $0.05)$ levels of cryptochlorogenic acid and coumaric acid than Red La Soda tubers and greater levels of cryptochlorogenic acid, neochlorogenic acid, and a flavonoid glucoside (flavonoid glucoside 1) than FL 1867 tubers. Red La Soda tubers had significantly greater $(P<0.05)$ levels of a flavonoid glucoside (flavonoid

TABLE 2. Correlation statistics between individual amino acid concentrations and 'Candidatus Liberibacter solanacearum' infection duration, zebra chip disease (ZC) symptom severity, and ' $\mathrm{Ca}$. L. solanacearum' titer ${ }^{\mathrm{a}}$

\begin{tabular}{|c|c|c|c|}
\hline $\begin{array}{l}\text { Cultivar, } \\
\text { compound }\end{array}$ & $\begin{array}{l}\text { Infection } \\
\text { duration }\end{array}$ & $\begin{array}{c}\text { ZC } \\
\text { symptom }\end{array}$ & Titer \\
\hline \multicolumn{4}{|l|}{ FL 1867} \\
\hline Asparagine & $-0.362 * *$ & $-0.481 * * *$ & -0.226 \\
\hline Aspartic acid & $-0.666^{* * * *}$ & $-0.665 * * *$ & $-0.313 *$ \\
\hline Glutamic acid & $-0.430 * * *$ & $-0.448 * * *$ & -0.253 \\
\hline Glutamine & 0.106 & 0.157 & 0.074 \\
\hline Methionine & $-0.456^{* * * *}$ & $-0.519 * * *$ & -0.212 \\
\hline Histidine & $0.342 * *$ & $0.449 * * *$ & 0.094 \\
\hline Isoleucine & $0.513 * * *$ & $0.543 * * *$ & 0.108 \\
\hline Leucine & $0.424 * * *$ & $0.587 * * *$ & 0.182 \\
\hline Lysine & $0.407 * *$ & $0.432 * * *$ & 0.183 \\
\hline Ornithine & $0.555 * * *$ & $0.636 * * *$ & 0.182 \\
\hline Phenylalanine & $0.602 * * *$ & $0.516^{* * * *}$ & 0.240 \\
\hline Proline & $0.478 * * *$ & $0.593 * * *$ & 0.113 \\
\hline Serine & $0.436 * * *$ & $0.530 * * *$ & 0.157 \\
\hline Tryptophan & $0.447 * * *$ & $0.495 * * *$ & $0.283 *$ \\
\hline Valine & -0.080 & -0.017 & -0.011 \\
\hline \multicolumn{4}{|l|}{ Red La Soda } \\
\hline Asparagine & $-0.628 * * *$ & $-0.657 * * *$ & $-0.371 * *$ \\
\hline Aspartic acid & $-0.666^{* * *}$ & $-0.804 * * *$ & $-0.465 * * *$ \\
\hline Glutamic acid & $-0.755^{* * * *}$ & $-0.810 * * *$ & $-0.426 * * *$ \\
\hline Glutamine & $-0.599 * * *$ & $-0.528 * * *$ & $-0.405 * *$ \\
\hline Methionine & $-0.648 * * *$ & $-0.641 * * *$ & $-0.435 * * *$ \\
\hline Histidine & 0.079 & $0.303^{*}$ & 0.140 \\
\hline Isoleucine & $0.610 * * *$ & $0.750 * * *$ & $0.385 * *$ \\
\hline Leucine & $0.713 * * *$ & $0.846^{* * *}$ & $0.512 * * *$ \\
\hline Lysine & $0.302^{*}$ & $0.459 * * *$ & 0.225 \\
\hline Ornithine & $0.563 * * *$ & $0.750 * * *$ & $0.415 * * *$ \\
\hline Phenylalanine & $0.384 * *$ & $0.525 * * *$ & $0.301 *$ \\
\hline Proline & $0.663 * * *$ & $0.823 * * *$ & $0.342 * *$ \\
\hline Serine & $0.492 * * *$ & $0.693 * * *$ & $0.311 *$ \\
\hline Tryptophan & 0.212 & $0.442 * * *$ & $0.291 *$ \\
\hline Valine & $0.343^{* *}$ & $0.553 * * *$ & 0.167 \\
\hline \multicolumn{4}{|l|}{ Russet Norkotah } \\
\hline Asparagine & $-0.524 * * *$ & $-0.489 * * *$ & -0.092 \\
\hline Aspartic acid & $-0.699 * * *$ & $-0.784 * * *$ & $-0.339 *$ \\
\hline Glutamic acid & $-0.722 * * *$ & $-0.704 * * *$ & $-0.328 *$ \\
\hline Glutamine & $-0.294^{*}$ & -0.219 & 0.076 \\
\hline Methionine & $-0.392 * *$ & $-0.448 * * *$ & -0.169 \\
\hline Histidine & $0.345^{*}$ & $0.389 * *$ & $0.340 *$ \\
\hline Isoleucine & $0.588 * * *$ & $0.641 * * *$ & $0.481 * * *$ \\
\hline Leucine & $0.728 * * *$ & $0.720 * * *$ & $0.525 * * *$ \\
\hline Lysine & $0.436 * * *$ & $0.456 * * *$ & $0.465 * * *$ \\
\hline Ornithine & $0.567 * * *$ & $0.597 * * *$ & $0.351 *$ \\
\hline Phenylalanine & $0.461 * * *$ & $0.466^{* * * *}$ & $0.396 * *$ \\
\hline Proline & $0.557 * * *$ & $0.604 * * *$ & $0.430 * *$ \\
\hline Serine & -0.147 & 0.091 & 0.161 \\
\hline Tryptophan & $0.288 *$ & $0.352 * *$ & $0.353 *$ \\
\hline Valine & $0.345^{*}$ & $0.340^{*}$ & $0.344^{*}$ \\
\hline
\end{tabular}

${ }^{a}$ All infected tubers were included in analyses regardless of infection duration. $N=52$ to 58 ; *,**, and $* * *$ indicate $P<0.05,0.010$, and 0.001 , respectively. glucoside 1) and quinic acid than FL 1867 and greater levels of another flavonoid glucoside (flavonoid glucoside 3) than Russet Norkotah tubers.

MANOVA confirmed that phenolic levels in ' $\mathrm{Ca}$. L. solanacearum'-infected tubers were significantly greater than levels in noninfected tubers $(\Lambda=0.326, F=6.513, P<0.001, N=210)$.

MANCOVA analysis was performed to examine differences due to cultivar and duration of ' $\mathrm{Ca}$. L. solanacearum' infection on phenolic levels while holding ' $\mathrm{Ca}$. L. solanacearum' titer as a covariable but, because the effect of ' $\mathrm{Ca}$. L. solanacearum' titer was nonsignificant $(\Lambda=0.142, F=1.321, P=0.213, N=164)$, MANOVA without the ' $C a$. L. solanacearum' titer co-variable was performed. MANOVA observed significant effects due to cultivar $(\Lambda=1.250, F=13.986, P<0.001, N=168)$, infection duration $(\Lambda=1.412, F=7.523, P<0.001, N=168)$, and plant replicate $(\Lambda=0.579, F=2.025, P=0.001, N=168)$ on tuber phenolic levels. There also was a significant interaction between cultivar and infection duration $(\Lambda=2.201, F=5.036, P<0.001$, $N=168$ ).

Subsequent ANOVAs observed that cultivar significantly $(P<$ $0.05)$ affected levels of most quantified phenolics, with the exception of a chlorogenic acid derivative, neochlorogenic acid, and the putative methyl salicylate dimer. According to Tukey HSD tests $(P<0.05)$, FL 1867 tubers had greater levels of the first chlorogenic acid peak than Red La Soda tubers and greater levels of quinic acid than both Red La Soda and Russet Norkotah tubers. Russet Norkotah tubers had greater levels of the second chlorogenic acid peak, cryptochlorogenic acid, and a flavonoid glucoside (flavonoid glucoside 2) than both FL 1867 and Red La Soda
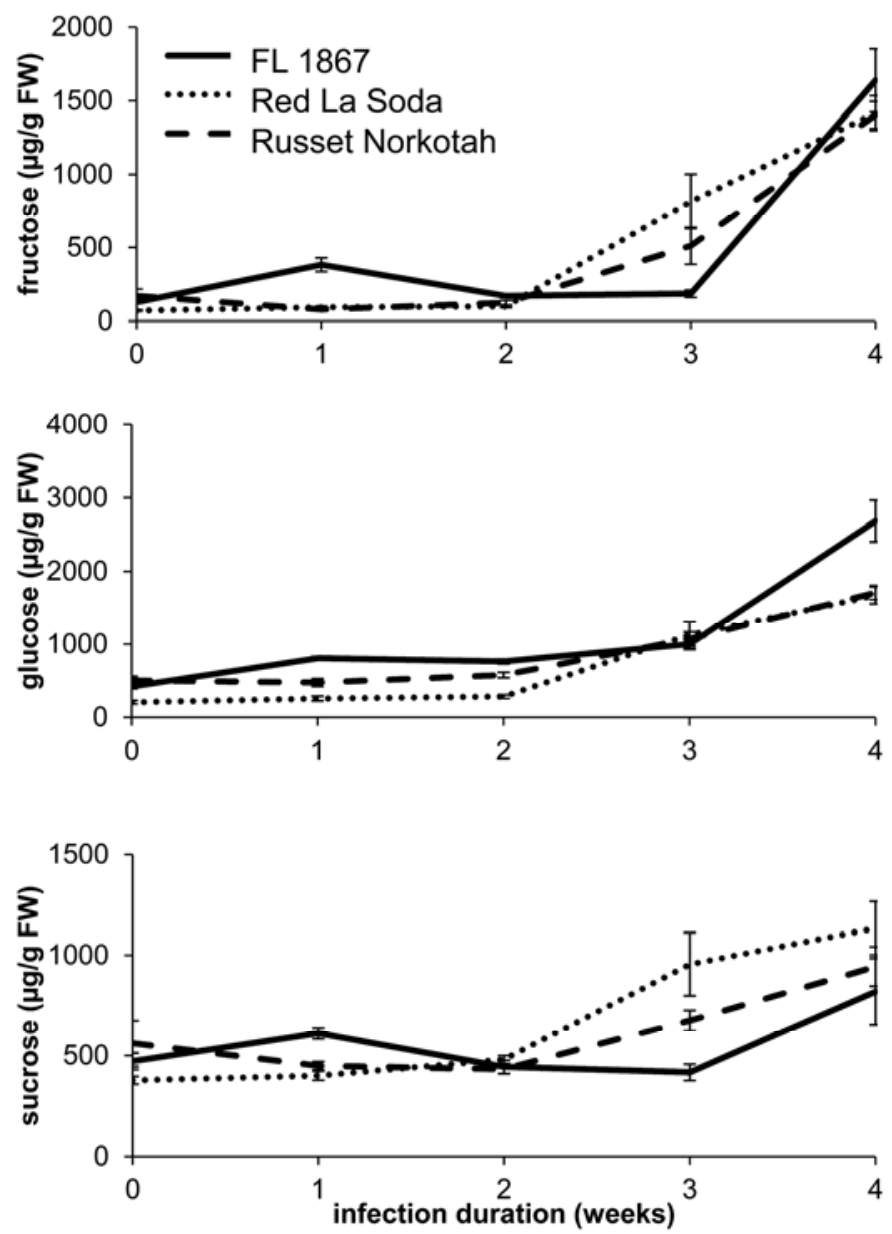

Fig. 2. Changes in fructose, glucose, or sucrose content over duration of 'Candidatus Liberibacter solanacearum' infection between different potato cultivars. Bars represent standard error. 
tubers, and greater levels of another flavonoid glucoside (flavonoid glucoside 1) than FL 1867 tubers. Red La Soda tubers had greater levels of coumaric acid than Russet Norkotah tubers and greater levels of a flavonoid glucoside (flavonoid glucoside 1) than FL 1867 tubers.

TABLE 3. Correlation statistics between sugar levels with infection duration, zebra chip disease (ZC) symptoms, or 'Candidatus Liberibacter solanacearum' titers ${ }^{\mathrm{a}}$

\begin{tabular}{|c|c|c|c|}
\hline $\begin{array}{l}\text { Cultivar, } \\
\text { compound }\end{array}$ & $\begin{array}{l}\text { Infection } \\
\text { duration }\end{array}$ & $\begin{array}{c}\text { ZC } \\
\text { symptom }\end{array}$ & Titer \\
\hline \multicolumn{4}{|l|}{ FL 1867} \\
\hline Fructose & $0.398 * *$ & $0.672 * * *$ & $0.431 * * *$ \\
\hline Glucose & $0.734 * * *$ & $0.696 * * *$ & $0.569 * * *$ \\
\hline Sucrose & -0.124 & 0.074 & 0.150 \\
\hline \multicolumn{4}{|c|}{ Red La Soda } \\
\hline Fructose & $0.723 * * *$ & $0.834 * * *$ & $0.635^{* * * *}$ \\
\hline Glucose & $0.761 * * *$ & $0.827 * * *$ & $0.607 * * *$ \\
\hline Sucrose & $0.631 * * *$ & $0.636 * * *$ & $0.475 * * *$ \\
\hline \multicolumn{4}{|c|}{ Russet Norkotah } \\
\hline Fructose & $0.862 * * *$ & $0.870 * * *$ & $0.326^{*}$ \\
\hline Glucose & $0.793 * * *$ & $0.744 * * *$ & $0.304 *$ \\
\hline Sucrose & $0.683 * * *$ & $0.628 * * *$ & 0.185 \\
\hline
\end{tabular}

Subsequent ANOVAs revealed that infection duration significantly $(P<0.05)$ affected tuber levels of every quantified phenolic compound. Phenolics were at significantly greater levels at 4 weeks of infection than any shorter infection duration (pairwise Tukey HSD, $P<0.05$ ). Likewise, tubers infected for 3 weeks had significantly greater $(P<0.05)$ levels of neochlorogenic acid, sinapic acid, epicatechin gallate, and two flavonoid glucosides than shorter infection periods. There also were significant $(P<$ $0.05)$ cultivar-infection duration interactions for every analyzed phenolic compound. Interactions likely were due to greater differences among cultivars in carbohydrate levels occurring when tubers were infected longer.

Regardless of cultivar, levels of most phenolic compounds were significantly $(P<0.05)$ positively correlated with infection duration and ZC symptoms (Table 4). For Red La Soda tubers, most phenolic compound levels were significantly positively correlated with ' $\mathrm{Ca}$. L. solanacearum' titers (except a flavonoid glucoside and quinic acid) (Table 4). However, most phenolic compound levels were not significantly correlated with ' $\mathrm{Ca}$. L. solanacearum' titer in FL 1867 or Russet Norkotah tubers (Table 4).

\section{DISCUSSION}

This study supported previous conclusions that ' $\mathrm{Ca}$. L. solanacearum' infection causes shifts in tuber biochemistry, including

TABLE 4. Correlation statistics between phenolic levels with infection duration, ZC symptoms, or 'Candidatus Liberibacter solanacearum' titers ${ }^{\mathrm{a}}$

\begin{tabular}{|c|c|c|c|}
\hline Cultivar, compound & Infection duration & ZC symptom & 'Ca. L. solanacearum' titer \\
\hline \multicolumn{4}{|l|}{ FL 1867} \\
\hline Chlorogenic acid $1^{b}$ & $0.674 * * *$ & $0.751 * * *$ & 0.050 \\
\hline Chlorogenic acid $2^{\mathrm{b}}$ & $0.707 * *$ & $0.746^{* * *}$ & 0.162 \\
\hline Chlorogenic acid derivative & $0.782 * * *$ & $0.747 * * *$ & 0.157 \\
\hline Coumaric acid & $0.656^{* * *}$ & $0.746 * * *$ & 0.166 \\
\hline Cryptochlorogenic acid & $0.592 * * *$ & $0.753 * * *$ & 0.227 \\
\hline Epicatechin gallate & $0.558 * * *$ & $0.663 * * *$ & 0.164 \\
\hline Flavonoid glucoside 1 & $0.615 * * *$ & $0.742 * * *$ & 0.223 \\
\hline Flavonoid glucoside 2 & $-0.424 * * *$ & $-0.536^{* * *}$ & -0.145 \\
\hline Flavonoid glucoside 3 & $0.597 * * *$ & $0.742 * * *$ & $0.317^{*}$ \\
\hline Methyl salicylate dimer & $0.634 * * *$ & $0.803 * * *$ & 0.252 \\
\hline Neochlorogenic acid & $0.545 * * *$ & $0.757 * * *$ & 0.168 \\
\hline Quinic acid & 0.221 & $0.504 * * *$ & 0.218 \\
\hline Sinapic acid & $0.653 * * *$ & $0.750 * * *$ & 0.126 \\
\hline \multicolumn{4}{|l|}{ Red La Soda } \\
\hline Chlorogenic acid $1^{\mathrm{b}}$ & $0.622 * * *$ & $0.750 * * *$ & $0.462 * * *$ \\
\hline Chlorogenic acid $2^{\mathrm{b}}$ & $0.525 * * *$ & $0.720 * * *$ & $0.478 * * *$ \\
\hline Chlorogenic acid derivative & $0.690 * * *$ & $0.834 * * *$ & $0.446 * * *$ \\
\hline Coumaric acid & $0.623 * * *$ & $0.740 * * *$ & $0.550 * * *$ \\
\hline Cryptochlorogenic acid & $0.723 * * *$ & $0.816^{* * * *}$ & $0.448 * * *$ \\
\hline Epicatechin gallate & $0.749 * * *$ & $0.785^{* * * *}$ & $0.498 * * *$ \\
\hline Flavonoid glucoside 1 & $0.617 * * *$ & $0.713 * * *$ & $0.522 * * *$ \\
\hline Flavonoid glucoside 2 & 0.180 & 0.195 & 0.176 \\
\hline Flavonoid glucoside 3 & $0.590 * * *$ & $0.703 * * *$ & $0.502 * * *$ \\
\hline Methyl salicylate dimer & $0.734 * * *$ & $0.797 * * *$ & $0.566^{* * * *}$ \\
\hline Neochlorogenic acid & $0.509 * * *$ & $0.562 * * *$ & $0.374 * *$ \\
\hline Quinic acid & $0.538 * * *$ & $0.597 * * *$ & 0.240 \\
\hline Sinapic acid & $0.653 * * *$ & $0.766^{* * * *}$ & $0.340^{*}$ \\
\hline \multicolumn{4}{|l|}{ Russet Norkotah } \\
\hline Chlorogenic acid $1^{\mathrm{b}}$ & $0.794 * * *$ & $0.773 * * *$ & 0.212 \\
\hline Chlorogenic acid $2^{\mathrm{b}}$ & $0.828 * * *$ & $0.763 * * *$ & 0.187 \\
\hline Chlorogenic acid derivative & $0.610 * * *$ & $0.720 * * *$ & 0.234 \\
\hline Coumaric acid & $0.666^{* * *}$ & $0.811^{* * * *}$ & 0.154 \\
\hline Cryptochlorogenic acid & $0.756^{* * * *}$ & $0.723 * * *$ & 0.121 \\
\hline Epicatechin gallate & $0.755^{* * *} *$ & $0.725 * * *$ & 0.056 \\
\hline Flavonoid glucoside 1 & $0.643 * * *$ & $0.674 * * *$ & $0.291 *$ \\
\hline Flavonoid glucoside 2 & $0.422 * * *$ & $0.426 * * *$ & -0.053 \\
\hline Flavonoid glucoside 3 & $0.635 * * *$ & $0.730 * * *$ & 0.201 \\
\hline Methyl salicylate dimer & $0.809 * * *$ & $0.809 * * *$ & 0.132 \\
\hline Neochlorogenic acid & $0.540 * * *$ & $0.566^{* * *}$ & 0.241 \\
\hline Quinic acid & $0.589 * * *$ & $0.621 * * *$ & 0.111 \\
\hline Sinapic acid & $0.726 * * *$ & $0.798 * * *$ & 0.075 \\
\hline
\end{tabular}

a $N=52$ to $58 ; *, * *$, and $* * *$ indicate $P<0.050,0.010$, and 0.001 , respectively.

${ }^{\mathrm{b}}$ In methanol, chlorogenic acid breaks down into two distinct peaks (7). 
increased levels of amino acids, carbohydrates, and phenolics $(24,34)$. Likewise, these results supported previous findings that increased phenolic and amino acid levels were strongly associated with ZC symptom progression over time $(20,24,34)$. However, in contrast to previous studies conducted on FL 1867 tubers (24), ' $C a$. L. solanacearum' titers were positively correlated with several amino acids, all analyzed carbohydrates, and most phenolics in Red La Soda tubers. Rashed et al. (24) quantified associations between ' $C a$. L. solanacearum' titer and shifts in tuber biochemical properties over infection durations of up to 9 weeks in FL 1867 tubers. It is conceivable that potential associations between compound levels and ' $\mathrm{Ca}$. L. solanacearum' titers that are observed in Red La Soda tubers occurred because infections in Red La Soda were progressing differently than the other cultivars. It was possible that a more controlled, consistent response to ' $\mathrm{Ca}$. L. solanacearum' infection occurred in Red La Soda tubers to result in significant associations between ' $\mathrm{Ca}$. L. solanacearum' titers and compound levels. By contrast, the triggering of biochemical shifts as a response to ' $\mathrm{Ca}$. L. solanacearum' infection for Russet Norkotah and FL 1867 tubers was more sporadic and associations between titers and compound levels became less clear.

In addition to possessing the only associations between compound levels and titers, Red La Soda potato developed more severe symptoms than Russet Norkotah potato after 3 or 4 weeks of ' $\mathrm{Ca}$. L. solanacearum' infection. Russet Norkotah potato developed more severe symptoms than FL 1867 potato after 3 or 4 weeks of infection as well. This was somewhat unexpected, because anecdotal observations suggested that Red La Soda appears to be less susceptible to ZC or potato psyllids than Russet Norkotah potato cultivars. However, chemical analyses of these potato varieties may provide an underlying clue as to why Red La Soda exhibited more severe fresh-cut potato symptoms than the other potato cultivars. In particular, Red La Soda, overall, had consistently greater levels of brown-product substrate phenolic compounds than FL 1867. Therefore, from the beginning, Red La Soda tubers appeared more "primed" for greater browning when infected with ' $C a$. L. solanacearum'.

It should be noted that greater levels of phenolics, as well as amino acids and sugars, might be more related to differences in potato phenology. In this case, Red La Soda tubers, even though harvested on the same date as the other cultivars, may have been at a later development stage than Russet Norkotah or FL 1867 tubers when sampled because Red La Soda plants were the first to senesce in the field. Plants may increase basal phenolic content when entering senescence (22), and this response could explain greater levels of phenolics present in Red La Soda potato tubers. Carbohydrate content also could be expected to increase in roots and tubers as plants enter senescence, especially if potato plants had extended time remaining in the field past optimal vine kill dates (26). Resultant sugar content increases could increase fried $\mathrm{ZC}$ symptoms. Therefore, future studies are warranted to explore the link between potato phenology, timing of vine kill for different potato cultivars, tuber phenolic and sugar content, and ZC symptom progression. Likewise, a comprehensive study comparing the effects of multiple years in multiple climates would be necessary to decode climatic and phenological effects on the levels of potato tuber biochemistry superimposed over the effects that ' $C a$. L. solanacearum' would have.

Amino acid responses to ' $\mathrm{Ca}$. L. solanacearum' infection were observed to be more complicated than previous reports $(24,34)$. In particular, amino acids with negatively charged side chains (aspartic acid and glutamic acid), their associated uncharged amino acids (asparagine and glutamine), and methionine all were at their greatest levels when infected for ' $\mathrm{Ca}$. L. solanacearum' for 1 week (albeit similar to noninfected levels in some cases) but were at the lowest when infected for 4 weeks. This differed from most of the remaining analyzed amino acids, which appeared to increase consistently with longer infection durations. The amino acids that peaked after 1 week may be disproportionately utilized by the pathogen or be differentially regulated during the host response to ' $\mathrm{Ca}$. L. solanacearum' infection. Future studies are needed to decode the meaning of these amino acids behaving divergently compared with those that increase consistently over time.

The observation that asparagine decreases after 1 week of ' $C a$. L. solanacearum' infection is particularly important, because multiple studies have suggested breeding potato with low asparagine content to avoid brown-colored acrylamide formation (23, 25 ). Because acrylamide is likely the cause of fried ZC symptoms, lowering asparagine content would indirectly increase ZC tolerance, an obvious goal of breeding programs. However, these results suggest that lowered amounts of reducing sugars might be a more desirable trait, because fried ZC symptoms consistently increased over time, regardless of the possible reductions of asparagine, as ' $C a$. L. solanacearum' infections progressed. Increased levels in other amino acids also may be more important in acrylamide production, especially in the case of ZC. Additional work is warranted to observe whether lowered levels of asparagine, other amino acids, or reducing sugars in potato cultivars could result in diminished fried ZC symptoms when infected with 'Ca. L. solanacearum'.

In conclusion, this study found that all analyzed sugars, most phenolics, and many amino acids were positively associated with infection duration and $\mathrm{ZC}$ symptoms, regardless of potato cultivar. This supports the idea that changes in host physiology as triggered by ' $\mathrm{Ca}$. L. solanacearum', and not a direct effect of the pathogen itself, may result in ZC symptomology because changes in phenolic content due to an induced host response would provide the substrates for observed browning in freshly cut infected tubers. The finding that Red La Soda potato possessed both greater ZC symptoms and phenolic content also is consistent with hypotheses about the host biochemical origins of ZC symptoms. Yet, the differential regulation of aspartic acid, glutamic acid, asparagine, glutamine, and methionine is an interesting and unexplained host response to ' $\mathrm{Ca}$. L. solanacearum' infection that warrants further exploration.

\section{ACKNOWLEDGMENTS}

This research was supported by a ZC SCRI/Industry-Funded MiniGrant, as well as the master ZC SCRI project, a USDA Specialty Crop Research Initiative grant (number 2009-51181-20176). We thank J. Gray, G. Aguilar, A. Fite, N. Goodell, and M. Henning for their assistance in the execution of this work; and Barrett's Potato Farms and CSS Farms for providing seed potato. Mention of trade names or commercial products in this publication is solely for the purpose of providing specific information and does not imply recommendation or endorsement by the United States Department of Agriculture (USDA). USDA is an equal opportunity provider and employer.

\section{LITERATURE CITED}

1. Alvarado, V. Y., Odokonyero, D., Duncan, O., Mirkov, T. E., and Scholthof, H. B. 2012. Molecular and physiological properties associated with zebra chip complex disease in potatoes and its relation with 'Candidatus Liberibacter' contents in psyllid vectors. PloS One 7:e37345.

2. Buchman, J. L., Fisher, T. W., Sengoda, V. G., and Munyaneza, J. E. 2012. Zebra chip progression: From inoculation of potato plants with Liberibacter to development of disease symptoms in tubers. Am. J. Pot. Res. 89:159-168.

3. Buchman, J. L., Heilman, B. E., and Munyaneza, J. E. 2011. Effects of Bactericera cockerelli (Hemiptera: Triozidae) density on zebra chip potato disease incidence, potato yield, and tuber processing quality. J. Econ. Entomol. 104:1783-1792.

4. Crosslin, J. M., Hamm, P. B., Eggers, J. E., Rondon, S. I., Sengoda, V. G., Munyaneza, and J. E. 2012. First report of zebra chip disease and 'Candidatus Liberibacter solanacearum' on potatoes in Oregon and Washington State. Plant Dis. 96:452. 
5. Crosslin, J. M., Olsen, N., and Nolte, P. 2012. First report of zebra chip disease and 'Candidatus Liberibacter solanacearum' on potatoes in Idaho. Plant Dis. 96:453.

6. Finotti, E., Bersani, E., Vivanti, V., and Friedman, M. 2011. Application of a functional mathematical quality index to asparagine, free sugar and phenolic acid content of 20 commercial potato varieties. J. Food Qual. 34:74-79.

7. Friedman, M. 1997. Chemistry, biochemistry, and dietary role of potato polyphenols, a review. J. Agric. Food Chem. 45:1523-1540.

8. Friedman, M., and Levin, C. E. 2008. Review of methods for the reduction of dietary content and toxicity of acrylamide. J. Agric. Food Chem. 56:6113-6140.

9. Gao, F., Jifon, J., Yang, X., and Liu, T.-X. 2009. Zebra chip disease incidence on potato is influenced by timing of potato psyllid infestation, but not by the host plants on which they were reared. Insect Sci. 16:399408.

10. Guenthner, J., Goolsby, J., and Greenway, G. 2012. Use and cost of insecticides to control potato psyllids and zebra chip on potatoes. Southwest. Entomol. 37:263-270.

11. Janse, J. D. 2012. Bacterial diseases that may or do emerge, with (possible) economic damage for Europe and the Mediterranean basin: Notes on epidemiology, risks, prevention and management on first occurrence. J. Plant Pathol. 94:S5-S29.

12. Levy, J., Ravindran, A., Gross, D., Tamborindeguy, C., and Pierson, E. 2011. Translocation of 'Candidatus Liberibacter solanacearum', the zebra chip pathogen, in potato and tomato. Phytopathology 101:1285-1291.

13. Liefting, L. W., Perez-Egusquiza, Z. C., Clover, G. R. G., and Anderson, J. A. D. 2008. A new 'Candidatus Liberibacter' species in Solanum tuberosum in New Zealand. Plant Dis. 92:1474.

14. Mayer, A. M. 2006. Polyphenol oxidases in plants and fungi: Going places? A review. Phytochemistry 67:2318-2331.

15. Miles, G. P., Buchman, J. L., and Munyaneza, J. E. 2009. Impact of zebra chip disease on the mineral content of potato tubers. Am. J. Pot. Res. 86:481-489.

16. Miles, G. P., Samuel, M. A., Chen, J., Civerolo, E. L., and Munyaneza, J. E. 2010. Evidence that cell death is associated with zebra chip disease in potato tubers. Am. J. Pot. Res. 87:337-349.

17. Munyazeza, J. E. 2012. Zebra chip disease of potato: Biology, epidemiology, and management. Am. J. Pot. Res. 89:329-350.

18. Munyaneza, J. E., Buchman, J. L., Sengoda, V. G., Fisher, T. W., and Pearson, C. C. 2011. Susceptibility of selected potato varieties to zebra chip potato disease. Am. J. Pot. Res. 88:435-440.

19. Munyaneza, J. E., Crosslin, J. M., and Upton, J. E. 2007. Association of Bactericera cockerelli (Homoptera: Psyllidae) with "zebra chip", a new potato disease in southwestern United States and Mexico. J. Econ. Entomol. 100:656-663.

20. Navarre, D. A., Shakya, R., Holden, J., and Crosslin, J. M. 2009. LC-MS analysis of phenolic compounds in tubers showing zebra chip symptoms. Am. J. Pot. Res. 86:88-95.

21. Nelson, W. R., Sengoda, V. G., Alfaro-Fernandez, A. O., Font, M. I., Crosslin, J. M., and Munyaneza, J. E. 2013. A new haplotype of 'Candidatus Liberibacter solanacearum' identified in the Mediterranean region.
Eur. J. Plant Pathol. 135:633-639.

22. Njoroge, S. M. C., Vallad, G. E., Kang, S., Koike, S. T., Bolda, M., Burman, P., Polonik, W., and Subbarao, K. V. 2011. Phenological and phytochemical changes correlate with differential interactions of Verticillium dahliae with broccoli and cauliflower. Phytopathology 101:523-534.

23. Olsson, K., Svensson, R., and Roslund, C.-A. 2004. Tuber components affecting acrylamide formation and colour in fried potato: Variation by variety, year, storage temperature and storage time. J. Sci. Food Agric. 84:447-458.

24. Rashed, A., Wallis, C. M., Paetzold, L., Workneh, F., and Rush, C. M. 2013. Zebra chip disease and potato biochemistry: Tuber physiological changes in response to 'Candidatus Liberibacter solanacearum' infection over time. Phytopathology 103:419-426.

25. Rommens, C. M., Yan, H., Swords, K., Richael, C., and Ye, J. 2008. Lowacrylamide French fries and potato chips. Plant Biotechnol. J. 6:843-853.

26. Sabba, R. P., Bussan, A. J., Michaelis, B. A., Hughes, R., Drilias, M. J., and Glynn, M. T. 2007. Effect of planting and vine-kill timing on sugars, specific gravity and skin set in processing potato cultivars. Am. J. Potato Res. 84:205-215.

27. Secor, G. A., and Rivera-Varas, V. 2004. Emerging diseases of cultivated potato and their impact on Latin America. Rev. Latinoam. Papa (Supl.) $1: 1-8$.

28. Secor, G. A., Rivera-Varas, V., Abad, J. A., Lee, I. M., Clover, G. R. G., Liefting, L. W., Li, X., and De Boer, S. H. 2009. Association of 'Candidatus Liberibacter solanacearum' with zebra chip disease of potato established by graft and psyllid transmission, electron microscopy, and PCR. Plant Dis. 93:574-583.

29. Sengoda, V. G., Munyaneza, J. E., Crosslin, J. M., Buchman, J. L., and Pappu, H. R. 2010. Phenotypic and etiological differences between psyllid yellows and zebra chip disease of potato. Am. J. Pot. Res. 87:4149.

30. Stadler, R. H., Blank, I., Varga, N., Robert, F., Hau, J., Guy, P. A., Robert, M. C., and Riediker, S. 2002. Acrylamide from Maillard reaction products. Nature 419:449-450.

31. Stark, J. C., and Love, S. L. 2003. Potato Production Systems. University of Idaho Agricultural Communications, Moscow.

32. Swisher, K. D., Munyaneza, J. E., and Crosslin, J. M. 2012. High resolution melting analysis of the cytochrome oxidase I gene identifies three haplotypes of the potato psyllid in the United States. Environ. Entomol. 41:1019-1028.

33. Vivanti, V., Finotti, E., and Friedman, M. 2006. Level of acrylamide precursors asparagine, fructose, glucose, and sucrose in potatoes sold at retail in Italy and in the United States. J. Food Sci. 71:81-85.

34. Wallis, C. M., Chen, J., and Civerolo, E. L. 2012. Zebra chip-diseased potato tubers are characterized by increased levels of host phenolics, amino acids, and defense-related proteins. Physiol. Mol. Plant Pathol. 78:66-72.

35. Wen A., Lin, H., and Gudmestad, N. C. 2012. Development of PCR assay using SSR primers for detection and genotyping of 'Candidatus Liberibacter solanacearum'. Pages 74-78 in: Proc. 11th Annu. SCRI Zebra Chip Rep. Session. F. Workneh, A. Rashed, and C. M. Rush, eds. Fredric Printing, Aurora, CO. 